\title{
A new therapy for refractory gastric cancer bleeding: endoscopic ultrasound-guided lauromacrogol injection
}
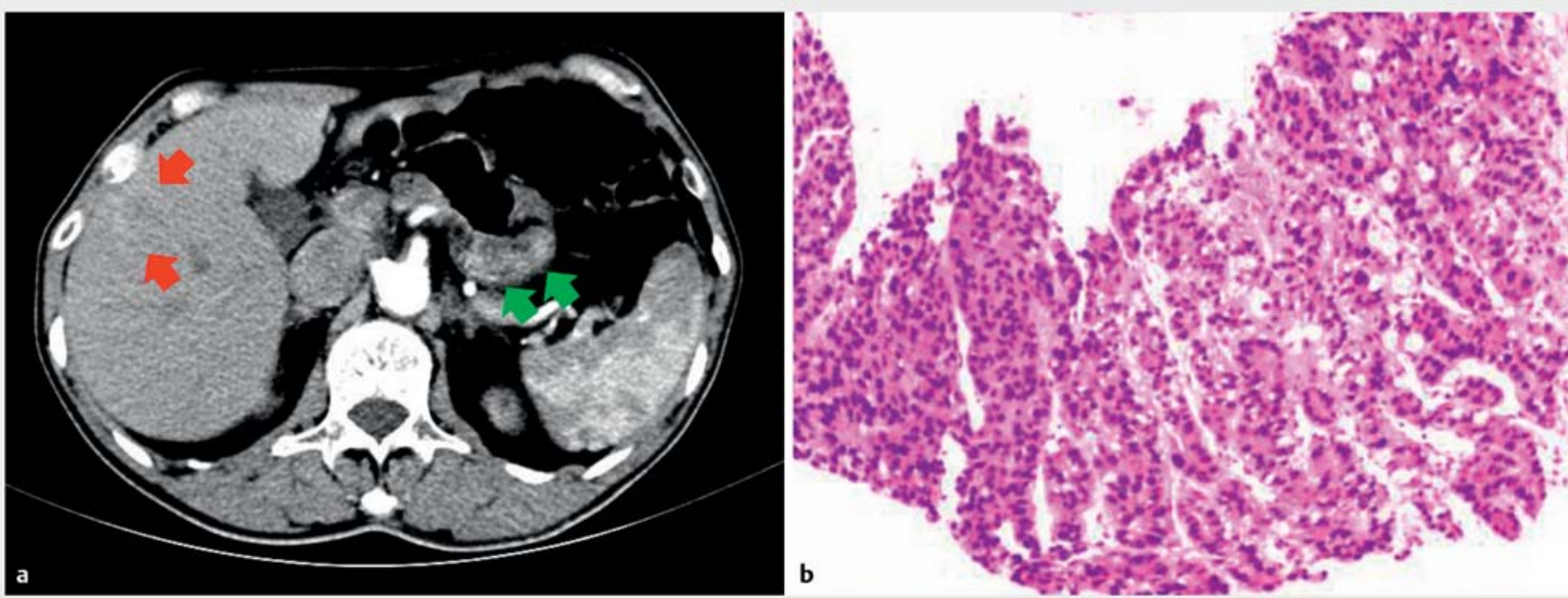

- Fig. 1 The patient was confirmed to have liver metastasis from gastric stump cancer. a Computed tomography showed that the residual stomach and anastomotic stoma were thickened and enhanced (green arrows). A hypoechoic lesion approximately $2 \mathrm{~cm}$ in size was observed in the liver (red arrows) and showed as slightly enhanced. b Metastatic tumor was confirmed by liver biopsy.

A 71-year-old man was admitted for intractable gastrointestinal bleeding because of residual gastric cancer with liver metastasis (> Fig.1). He presented having had three episodes of hematemesis or melena in the previous 30 days. Conventional endoscopic management for bleeding of unresectable gastric cancer is challenging because of the low clinical success rate and high amount of rebleeding [1]. After careful discussion with the patient and his family, treatment using endoscopic ultrasound (EUS)-guided lauromacrogol injection was decided.

Repeat endoscopy revealed persistent active bleeding from the anastomosis of the residual stomach ( $\mathbf{F i g . 2}$ ). A vessel originating from the submucosa and extending into the mucosa was identified using EUS-aided color Doppler imaging ( $\triangleright$ Video 1 ). EUS-guided lauromacrogol injection was performed using a 22-gauge needle (Echo 3-22; Cook Endoscopy, Winston-Salem, NC, USA). Moreover, color Doppler imaging confirmed the absence of blood flow after therapy ( $\triangleright$ Video 1 ). Endoscopy immedi-

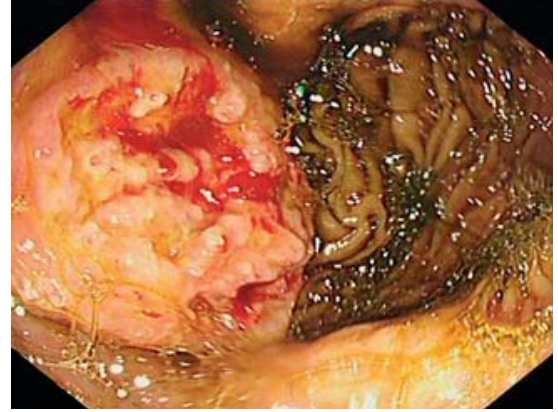

- Fig. 2 Endoscopy revealed persistent active bleeding in the residual stomach even after proton pump inhibitor and somatostatin were used.

ately after the injection confirmed the absence of bleeding ( $>$ Fig.3). The patient was followed for more than 6 months without further episodes of gastrointestinal bleeding. No adverse events or complications were recorded during or after the procedures.

The efficacy of EUS-guided therapy of nonvariceal upper gastrointestinal bleeding has been described. Series have been published with success rates of $88 \%-$

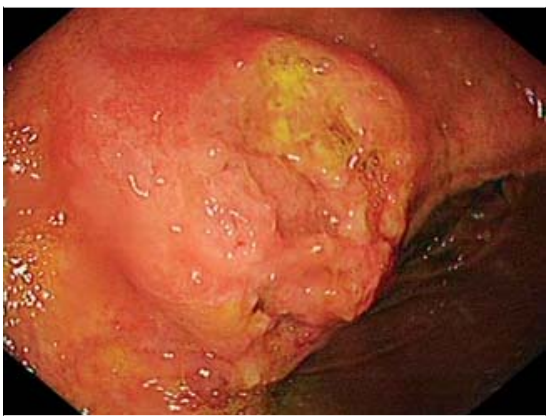

- Fig. 3 Endoscopy immediately after the injection confirmed the absence of bleeding.

$100 \%$ for the treatment of Dieulafoy's lesions, pancreatic/gastroduodenal artery pseudoaneurysms, gastrointestinal stromal tumors, periampullary tumors, duodenal ulcers, and intractable marginal ulcers after Roux-en-Y gastric bypass [2-4]. To our knowledge, EUS-guided lauromacrogol injection for the treatment of refractory gastric cancer bleeding has not been reported in this setting. 


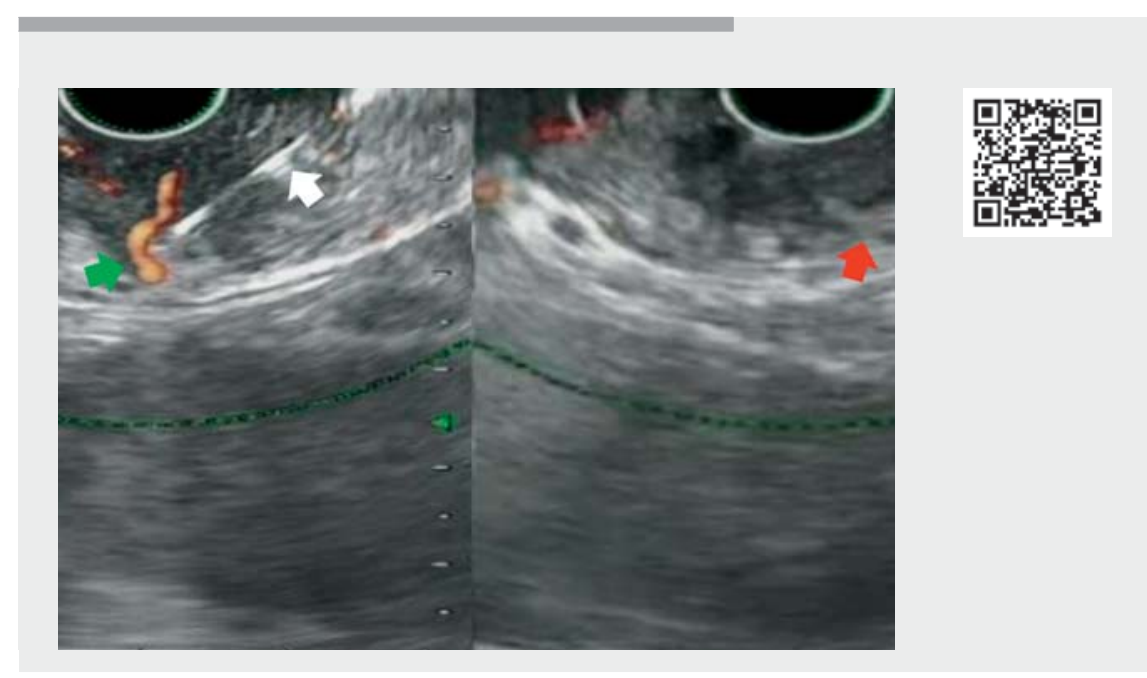

$\checkmark$ Video 1 Endoscopic ultrasound (EUS) showed a persistent bleeding from a vessel in the submucosa identified by color Doppler imaging. EUS-guided injection of $12 \mathrm{~mL}$ lauromacrogol was performed using a 22 -gauge needle. EUS then showed the absence of blood flow at the site, with cutoff of the vessel.

In conclusion, EUS-guided angiotherapy may be a safe and effective therapeutic option in patients with refractory bleeding gastric cancer considered unsuitable for surgery.

Endoscopy_UCTN_Code_TTT_1AO_2AD

Funding

National Natural Science Foundation

of China

http://dx.doi.org/10.13039/

501100001809

81800467,81770637

\section{Competing interests}

The authors declare that they have no conflict of interest.

\section{References}

[1] Kawabata H, Hitomi M, Motoi S. Management of bleeding from unresectable gastric cancer. Biomedicines 2019; 7: 54

[2] Ramachandran BS, Abraham B, Haridas AC et al. EUS-aided diagnosis and treatment of bleeding gastric Dieulafoy's lesion (with video). Endosc Ultrasound 2020; 9: 200-201

[3] Sharma M, Somani P, Sunkara T et al. Endoscopic ultrasound-guided management of bleeding periampullary tumor. Endoscopy 2018; 50: E192-E193

[4] De Angelis CG, Cortegoso VP. Endoscopic ultrasound-guided treatments for non-variceal upper GI bleeding: a review of the literature. J Clin Med 2020; 9: 866

Bibliography

Endoscopy 2022; 54: E151-E152

DOI 10.1055/a-1398-5196

ISSN 0013-726X

published online 16.4.2021

(c) 2021. Thieme. All rights reserved.

Georg Thieme Verlag KG, Rüdigerstraße 14, 70469 Stuttgart, Germany

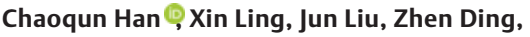
Xiaohua Hou

Division of Gastroenterology, Union Hospital, Tongji Medical College, Huazhong University of Science and Technology, Wuhan, China

Corresponding author

\section{Zhen Ding, MD, PhD}

Division of Gastroenterology, Union Hospital, Tongji Medical College, Huazhong University of Science and Technology, 1277 Jiefang Avenue, Wuhan, Hubei Province, P. R. China 430022 docd720@126.com

\section{ENDOSCOPY E-VIDEOS}

https:|/eref.thieme.de/e-videos

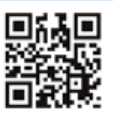

Endoscopy E-Videos is an open access online section, reporting on interesting cases and new techniques in gastroenterological endoscopy. All papers include a high quality video and all contributions are freely accessible online. Processing charges apply (currently EUR 375), discounts and wavers acc. to HINARI are available.

This section has its own submission website at https://mc.manuscriptcentral.com/e-videos 